help to handle this complexity. In addition, pest problems (such as root-knot nematodes) are not always widespread, and thus are not of general interest.

Ninety-five percent of those responding said CALEX/Cotton was very easy or fairly easy to use. About $90 \%$ responded that availablesupport was very valuable or fairly valuable. Even though CALEX/Cotton was designed to be easy to use, we found it necessary to providefundamental computer literacy training.

CALEX/Cotton has been well received by the cotton industry. Because of the close involvement of the industry during the development of the program, its strengths and limitations are appreciated by those using it. The program is recognized as a prototype with much development yet to occur and the full potential of the technology yet to be realized.

Expert support systems hold the promise of acting as a conduit to improve the flow of technology and knowledge from researchers to agriculturists. Demands for more information in this new decade will require new methods for handling information. Economic constraints and legal restrictions will continueto increaseand will increasingly require that agricultural chemical inputs be justified. CALEX technology can meet this challenge by taking a systems approach to managing data and information that encompass as much of the production system as possible.

Peter B. Goodell is Area IPM Advisor, Statewide IPM Project, Kern County; Richard E. Plant is Professor, Department of Agronomy, UC Davis; Thomas A. Kerby is Cotton Extension Specialist, Department of Agronomy, UC Davis; Joyce F. Strand is Computer System Manager, Statewide IPM Project, Davis; L. Ted Wilson is Professor, Department of Entomology, UC, Davis; Lowell Zelinski is Agronomist, Harvey Campbell and Associates, Fresno, California; Julie A. Young is Staff Research Associate, Department of Agronomy, UC Davis; Andrew Corbett is Research Assistant, Department of Entomology, UC Davis; R. D. Horrocks is Professor, Brigham Young University, Provo, Utah; and Ronald $N$. Vargas is Farm Advisor, UC Cooperative Extension, Madera County.

The authors would like to acknowledge key individuals who have worked on this project: $C$. Ver Linden, R. Freisen, and C. Estill for field assistance; Don Grimes for his general expertise; the UC IPM Computer Staff, especially L. Bernheim,D.Seaver, and M.Brush;S.Schoenig, $M$. Adams, and J. Kwan for additional programming support; Cotton Farm Advisors Bruce Roberts, Kater Hake, Bill Weir, and Doug Munier and the cooperators who showed tremendous patience with the program's development. Support for this project was provided by the Statewide IPM Project, BASF Systems Corporation, and Rhone-Poulenc Ag Company.

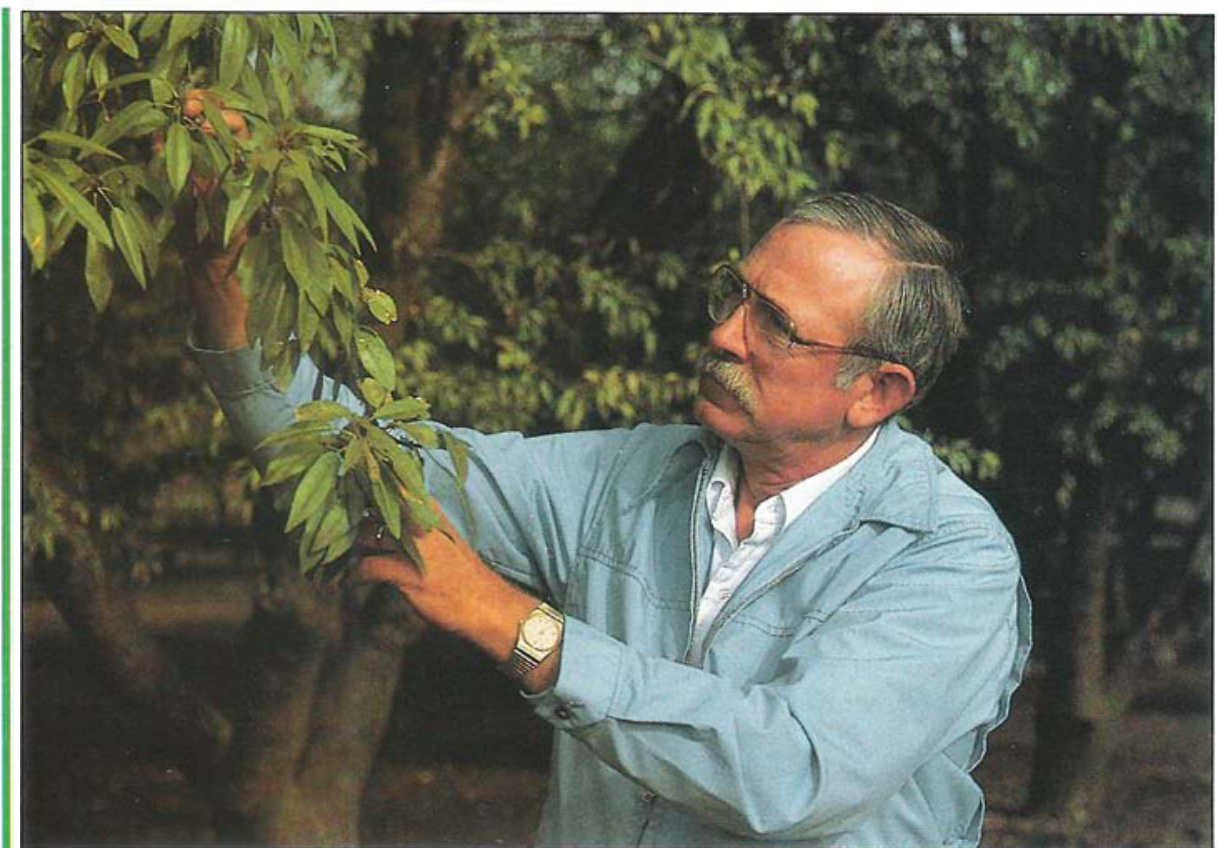

Monitoring for pests is a fundamental element in integrated pest management. Here, Area IPM Advisor Bill Barnett checks almond leaves for twospotted spider mites.

\title{
IPM California's almond IPM program
}

\author{
Karen Klonsky a Frank Zalom a Bill Barnett
}

\section{Almond pest control was an early focus for UC IPM researchers. That work continues today. IPM prac- tices for almond insect manage- ment are now used by most grow- ers, and have reduced California's annual pesticide bill by an esti- mated \$4.1 million.}

Before navel orangeworm, peach twig borer was the key pest in California almond orchards. Annual dormant season treatments were generally successful for control, but borer populations still surged from time to time. With no reliable way to monitor pest populations, growers could only cope with the pest by treating their orchards more frequently. Because the insecticides killed beneficial insects along with the pests, mite damage to the orchards increased.

In the 1960s, changing harvest techniques brought a new pest: navel orangeworm. Rather than knocking the nuts from the trees with mallets and poles, growers were harvesting with mechanical shakers that left morenuts on the trees for the winter. Because shaker harvesting was fast, growers could wait for the almond hulls to split uniformly throughout the orchard before beginning to harvest. University of California research had shown in the 1950s that orchard sanitation and early harvest could help control navel orangeworm, but few growers consciously followed either practice.

In 1976, insecticides were registered specifically for navel orangeworm control. The lack of reliable pest monitoring led to illtimed chemical treatments that had to be repeated to ensuretheir effectiveness. Again, theinsecticidesallowed secondary pests such as mites and San Jose scale to thrive, prompting still more chemical treatments.

\section{Integrated pest management}

Cultural practices. As early as the 1950s, UC researcher Francis Summers identified orchard sanitation and early harvest as cultural techniques for navel orangeworm control in almonds. Leo Caltagirone (UC Berkeley) and his colleagues published additional research on sanitation and early harvest in 1968. In the mid-1970s, USDA scientists led by Charles Curtis developed the practical application of orchard sanitation 
and conducted large-scale field trials to demonstrate its effectiveness.

Two chemicals, azinphosmethyland carbaryl, were registered specifically for navel orangeworm control in the spring of 1976, the same year that Richard Rice (UC Davis) developed egg traps to monitor navel orangeworm populations. Entomologist Martin Barnes (UC Riverside) and his students developed detailed information on navel orangeworm phenology and damage levels that helped growers schedule insecticide treatments.

In 1979, Extension EntomologistClarence Davis instituted an IPM project that was sponsored partly by Smith-Lever IPM funds and partly by the Almond Board of California. His purpose was to validate research results and assemble them into a pest management package that could be used by growers.

In 1981 and 1982, a group of Extension IPM Specialists and Farm Advisors conducted a series of tests in 33 differentorchards to demonstrate the combined effects of orchard sanitation, early harvest, and egg trap monitoring. Their results showed that the program could successfully reduce damage from navel orangeworm while reducing the number of insecticide treatments.

Maintaining beneficials. UC Berkeley entomologist Marjorie Hoy demonstrated in 1978 that the insecticides used for navel orangeworm control disrupted the natural enemy complex that helps control spider mites in almond orchards. Subsequently, she and her coworkers developed strains of the predatory mite Metaseiulus occidentalis that could survive treatments with some insecticides used for navel orangeworm control. Treatment thresholds were developed for the Pacific mite by Barnes's students Andrews and LaPre. A team of UC researchers also developed a presence-absence sampling plan for the Tetranychus mites.

Extension Specialists and Farm Advisors have introduced various components of the integrated mite management program since the research began in 1978. The mite monitoring program was introduced to the San Joaquin Valley in a series of demonstration orchards by Extension IPM Farm Advisors in 1983, and went statewide in 1984.

Richard Rice tested pheromones as a monitoring tool for peach twig borer in the 1970s. Later, he teamed up with Jay Brunner to develop a phenology model for improving the timing of in-season insecticide treatments. The pheromone traps and phenology models that help growers monitor San Jose scale and oriental fruit moth populations and improve the timing of inseason insecticide treatments of both pests were developed by Rice and his coworkers beginning in themid-1970s. Pheromonetraps were also used for peach twig borer and San
Jose scale in the demonstration orchards. Similar monitoring techniques for oriental fruit moth were demonstrated in that pest's limited areas of infestation in 1983.

Through publications and an annual research conference, the Almond Board of California has done an excellent job of keeping growers up to date on IPM research at the University. Cooperative Extension Farm Advisors in the major almond growing counties hold annual grower meetings where they inviteresearchers todiscuss their work. The Farm Advisors also issue newsletters and media releases. A manual, Integrated Pest Management for Almonds, was produced by the Statewide IPM Project in 1985. "Almond Pest Management Guidelines," also produced by the Statewide IPM Project, is updated annually or as relevant pesticide regulations change.

\section{IPM for almond insect pests}

In almond orchards, IPM is a season-long process beginning in the dormant season and extending beyond harvest:

Dormant season: pruning (for good nut removal and good spray coverage), weed control (toeliminate winter refuge for pests), orchard sanitation (mummy removal), and dormant sprays (organophosphate insecticides and oil)

Growing season: in-season insecticide treatment (if two or more mummy nuts remain on each tree or no early harvest is planned)and monitoring navelorangeworm egg populations with egg traps

Hullsplit and harvest: early harvest (the most important IPM technique for navel orangeworm control), quickremoval of fallen nuts from the orchard floor (to prevent further development of navel orangeworms infesting the hulls), and artificial drying or fumigation (if nuts have been infested with navel orangeworms before harvest)

Spider mites: regular sampling of spider mites and their natural enemies, using a presence-absence method developed at UC

\section{IPM user survey - 1985}

The data in table 1 compare the results of two mail surveys on the adoption of IPM practices by California almond growers. The 1981 survey was conducted by J. C. Headley, and the 1985 survey was conducted by Frank Zalom and Karen Klonsky.

In the 1985 survey, growers were asked when they had first heard about integrated pest management. Almost one-third of all respondents had never heard of IPM. Of those who had heard of IPM, more than onethird placed that awareness before 1977, fewer than one-third placed it from 1977 and 1980 , and about one-third placed it after 1980. Awareness of IPM is not the same thing as using IPM practices. A grower may be using techniques that qualify as IPM practices, but be unfamiliar with the terms IPM and integrated pest management. In fact, the 1985 survey revealed that severalgrowers using integrated pest management practices said they had never heard of IPM.

When asked how they first heard about IPM, the most common information source was UC Cooperative Extension. Of the growers who had heard of IPM, $28 \%$ named Cooperative Extension as the source of their initial exposure, $20 \%$ named trade publications, and $17 \%$ named farm supply dealers. Other sources included newspapers, private consultants, neighbors, and schools.

When asked about sources of pest management information, about $87 \%$ of the respondents cited Cooperative Extension publications. Of those respondents, $34 \%$

TABLE 1. Implementation of pest management practices, 1981 and 1985

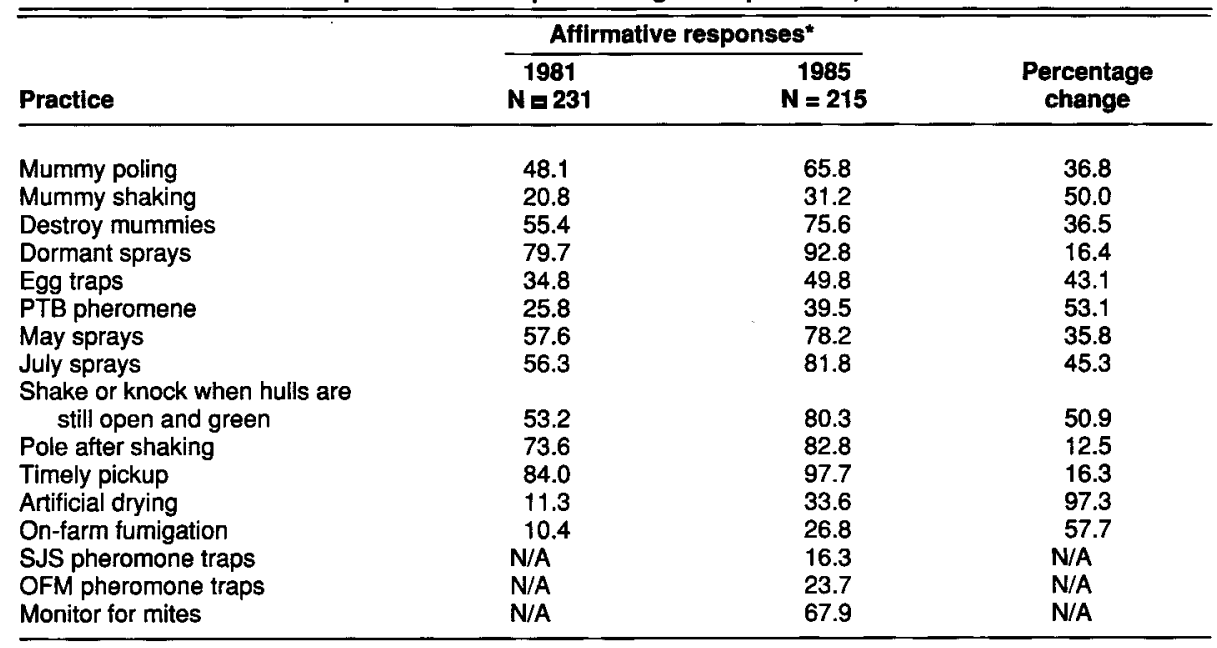

"Answers to the 1981 survey could be "yes" or "no," so the affirmative response was "yes." In 1985, the answers could be "always," "sometimes," or "never," so the affirmative responses were "sometimes" and "always." 
found them very useful, $44 \%$ found them useful, and $22 \%$ found them sometimes useful; only one respondent said that the publications were not useful. Other sources from Cooperative Extension included Farm Advisors, meetings, and short courses.

About $82 \%$ of the growers had received information from their county Farm Advisors. Of these respondents, $98 \%$ described the information as useful. Extension meetings and short courses were well attended, but were mentioned less frequently than Extension publications or the local Farm Advisors. All who had attended Extension meetings found them to be useful. Only one grower who had attended a short course saidit was notuseful. Other sources of written

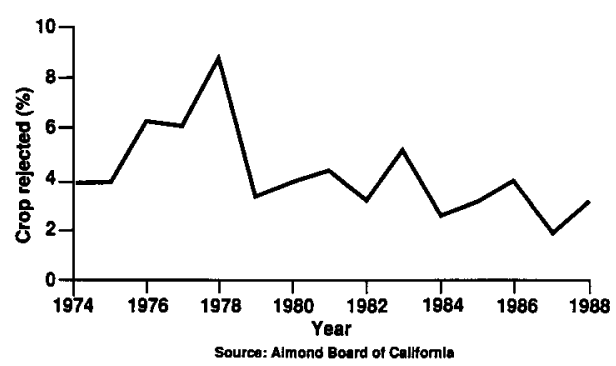

Fig. 1. Almond crop damage from navel orangeworm, 1974 to 1988.

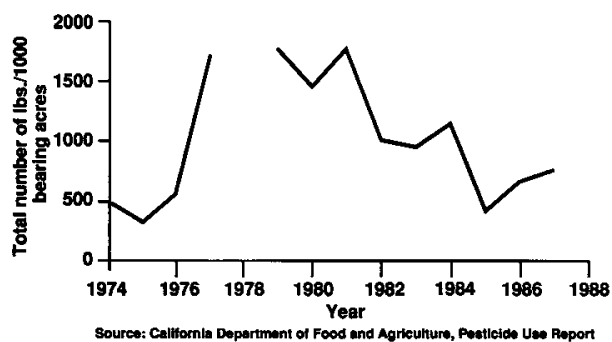

Fig. 2. Pounds of pesticide applied per 1,000 acres of almonds for navel orangeworm control, 1974 to 1987.

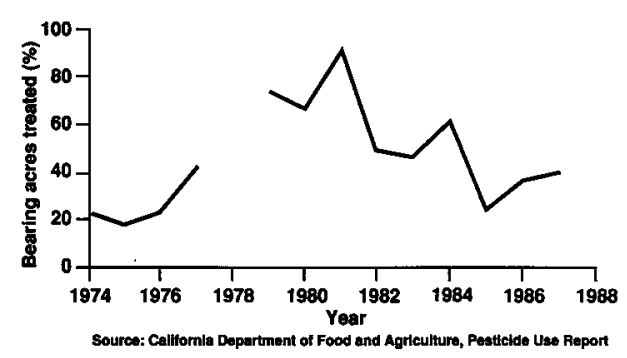

Fig. 3. Almond acreage treated with pesticides for navel orangeworm control, 1974 to 1987. material included newspapers, trade publications, and several industry newsletters and publications.

Elsewhere in the survey, growers found a list of 16 pest management practices and were asked how often they implemented each one: always, sometimes, or never. We interpreted "sometimes" to mean that the grower was aware of the control practice, but in some years determined it was not necessary or not economically feasible. For example, in a light crop year with storms after harvest or significant bird activity in the trees, a grower might decide not to remove mummies by poling because with so few mummies remaining in the trees, the labor cost would not be justified.

\section{Comparison to 1981 survey}

Headley's 1981 survey has provided a benchmark for looking at adoption trends. For each pest management practice, the implementation percentage was higher in 1985 than in 1981 (table 1). San Jose scale and oriental fruit moth pheromone traps and monitoring for mites were not included in the 1981 survey, since these methods were not extended to any significant degree until after that time.

The possible answers about adoption of various practices differed on the 1981 and 1985 surveys. In the earlier survey, respondents could answer only "yes" or "no," rather than "always," "sometimes," or "never."

\section{Trends in almond pest control}

Statistical tables provided by the Almond Board of California and the annual "Pesticide Use Report" published by the California Department of Food and Agriculture were used to determine possible effects of IPM research and extension activities on the California almond industry. Many factors influence pest status in almonds in a given year. Therefore, trends in tangible factors such as cropdamageand pesticide use might be more indicative of a program's impact than data reported for a single year.

\section{Crop damage}

Figure 1 shows the proportion of the almond crop statewide rejected due to worm damage in each of the years 1974 through 1988. This damage is primarily due to navel orangeworm and secondarily due to peach twig borer, although this may be affected by region, weather conditions, and individual orchard horticultural practices.

Total almond production in California averaged 449 million kernel pounds per year for the period 1982 through 1988. The average price per pound received by growers during this period was $\$ 1.07$. The reduction in damage of $1.8 \%$ has meant an additional 8.1 million pounds of production or $\$ 8.7$ million per year. Individual producers also

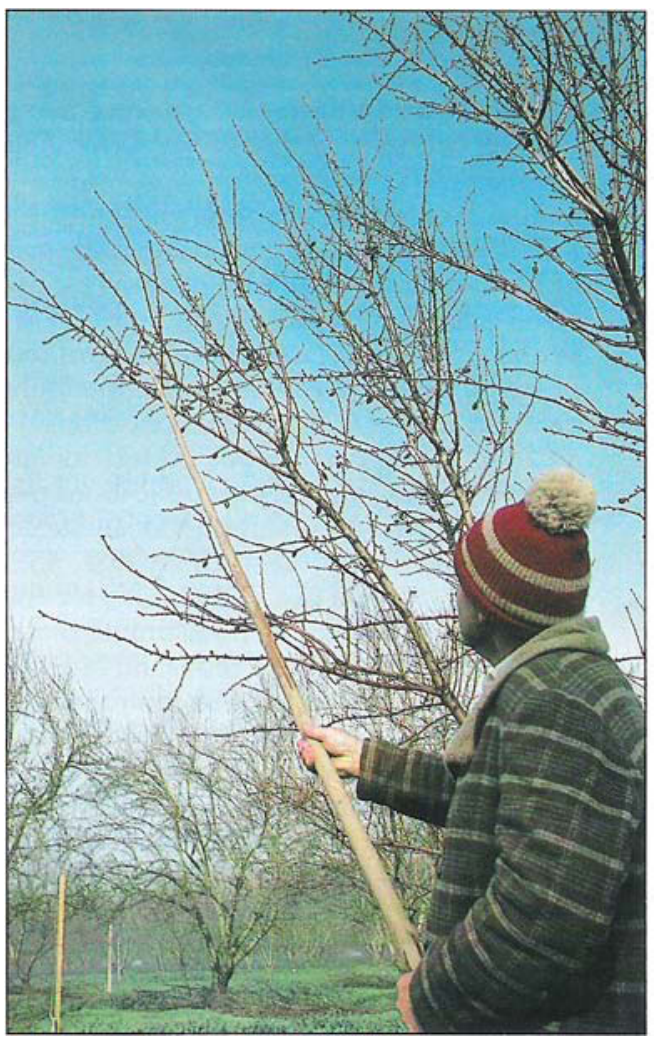

Machine harvesting leaves more nuts (mummies) on the trees after harvest. If not shaken from the trees or knocked down with poles, the mummies will provide overwinter harborage for navel orangeworm larvae.

gained additional benefits from a reduction in damage as bonuses are awarded by many handlers for delivering almonds with less than 3\% damage. Lower damage on an industry-widebasis makes Californiaalmonds more competitive in both domestic and world markets.

\section{Pesticide use}

Assessing theeffect of an IPM programbased on the amount of pesticide applied to the crop statewide is difficult, since pesticide availabilities change over time, along with application rates for the various materials. The principal insecticides used for in-season control of navel orangeworm and peach twig borer in almond, azinphosmethyl and carbaryl, haveconsistently represented more than $80 \%$ of all applications and pounds of insecticides applied. Diazinon, phosmet, and permethrin make up most of the remaining insecticides used for in-season worm control in almonds. However, Diazinon is most often used as a dormant spray in almond.

No insecticides were registered specifically for navel orangeworm until 1976, so we can assume that the materials mentioned above were used principally for peach twig borer in 1974, 1975, and to a large extent in 1976. Figure 2 shows the total number of pounds of these insecticides applied per thousand bearing acres of almonds in each year from 1974 through 1987, as reported in the annual CDFA "Pesticide Use Report." 
No data on azinphosmethyl appeared in the 1978 report, so we omitted that year from our results.

Insecticide use dropped dramatically from 1982 through 1987, probably as a result of IPM research - cultural controls for the navel orangeworm developed by UC IPM, better monitoring of navel orangeworm and peach twig borer populations, and therefore better timing of insecticide applications and the reduced price per pound for almonds. Annual insecticide applications per thousand bearing acres of almond saveraged 786 pounds from 1982 through 1987, 45\% below the average of 1,430 pounds for the period 1979 through 1981. Assuming that a constant 360 pounds per thousand bearing acres were used primarily to control peach twig borer, the reduction in pounds used for navel orangeworm control would be $60 \%$.

Figure 3 shows the pesticide use information reported as a proportion of bearing acres treated. Pesticide use increased dramatically afterazinphosmethyl and carbaryl were registered for navel orangeworm on almonds. Approximately $21 \%$ of the total bearing almond acreage was treated annually between 1974 and 1976. The percentage of bearing almond acres that were treated peaked in 1981 at about $92 \%$, and with an average of about $77 \%$ from 1979 to 1981 .

The almond insect IPM program has resulted in an estimated $\$ 4.1$ million reduction in pesticidecosts. In the 1985 grower survey, $53 \%$ of growers reported spraying pesticides as part of their routineworm control practices as compared to $77 \%$ in the 1981 grower survey - a $24 \%$ reduction. We also know from the 1985 grower survey that those growers who sprayed used an average of 1.43 sprays per acre. The average bearing acreage between 1982 and 1988 was 387,000 acres. The $24 \%$ reduction in sprays has meant a reduction of 124,614 acre-sprays per year. At a cost of $\$ 32$ per spray, this has meant a direct savings in input costs to California almond growers of over $\$ 4$ million per year. This all adds up to an estimated benefit of $\$ 12.8$ million, including an increase of $\$ 8.7$ million in revenues resulting from increased salable production and a decrease of $\$ 4.1$ million in pesticide costs.

Additional benefits with less tangible economic values have accompanied the reduction in insecticide use: less risk of injury to the grower or farm workers, fewer secondary pest outbreaks (principally spider mites) resulting from disruption of the natural enemy complex, and less toxic wastewater and fewer empty pesticide cannisters needing disposal.

Karen Klonsky is Extension Economist, UC Davis; Frank G. Zalom is Director, IPM Implementation Group, UC Davis; and Bill Barnett is Area IPM Advisor, based at the Kearney Agricultural Center in Parlier.

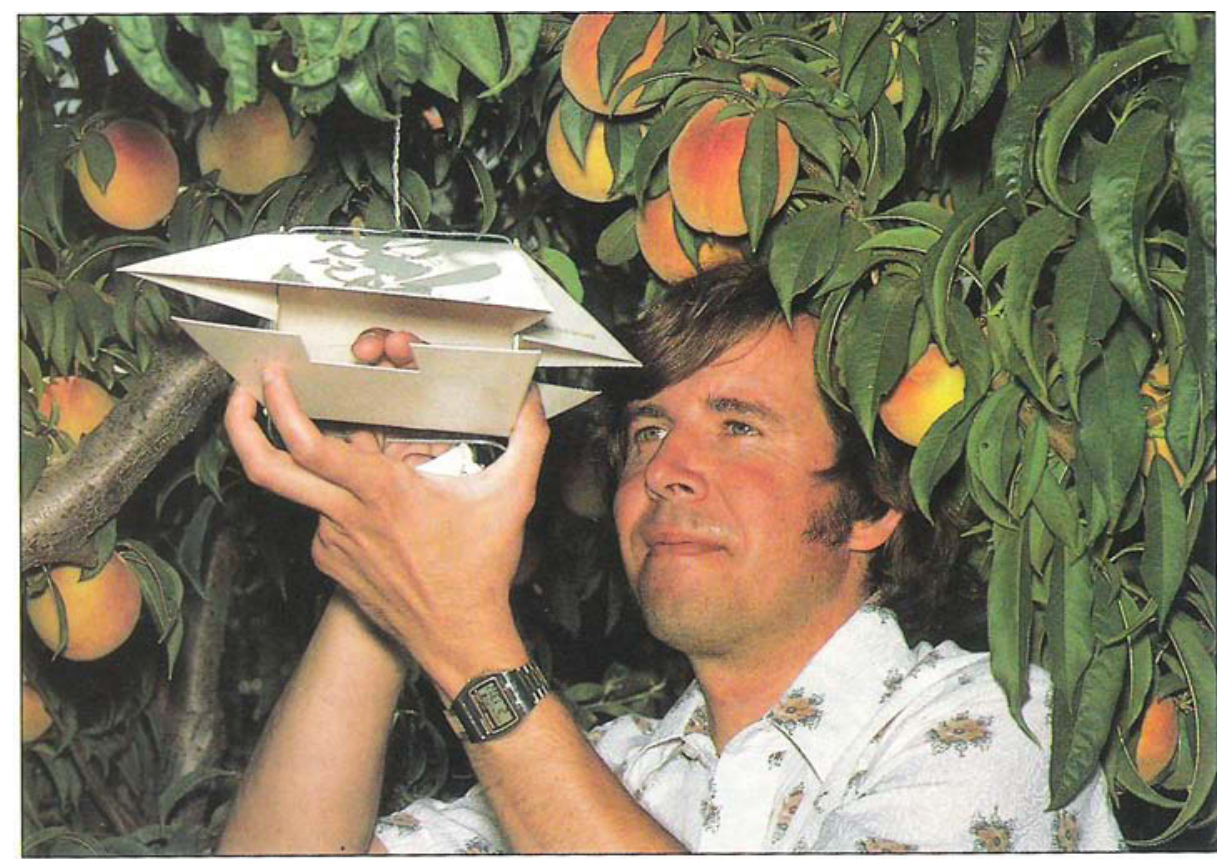

Frank Zalom, Director of the IPM Implementation Group, places a pheromone attractant into a codling moth trap. Moths drawn by the scent are caught on the trap's sticky inner surface.

\section{IPM Research results: Statewide IPM's first 10 years}

\author{
James I. Grieshop a Robert A. Pence
}

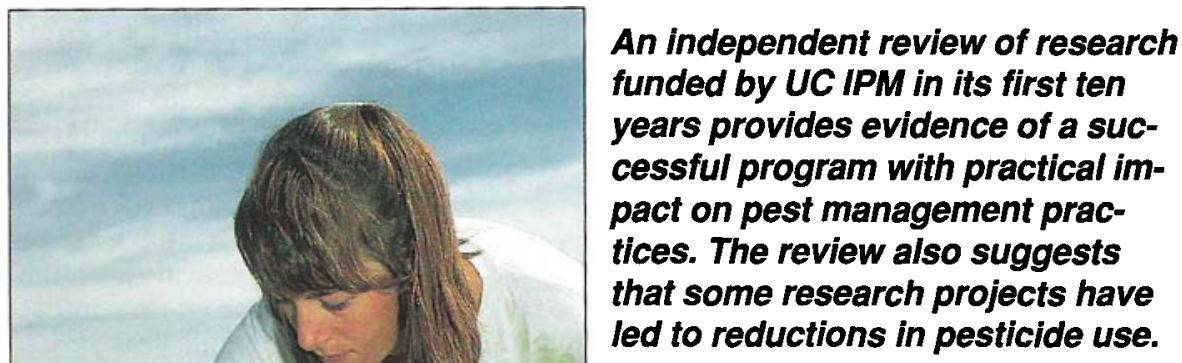

\begin{abstract}
An independent review of research funded by UC IPM in its first ten years provides evidence of a successful program with practical impact on pest management practices. The review also suggests led to reductions in pesticide use.
\end{abstract}

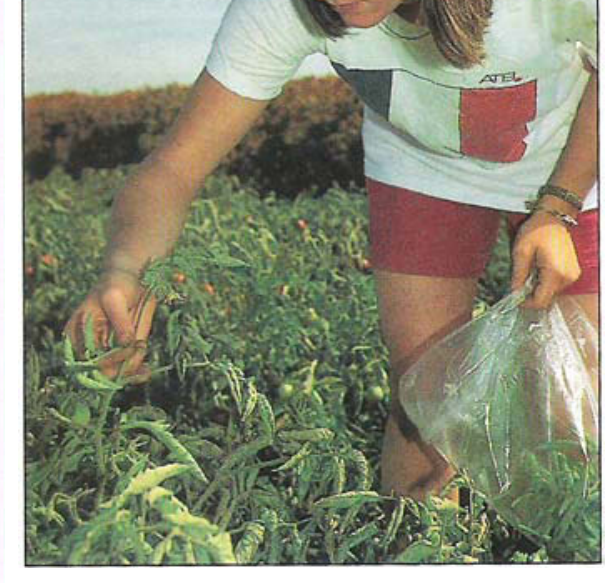

Sampling for tomato fruitworm (Heliothis zea) eggs in processing tomatoes. 